\title{
Retropharyngeal phlegmon and cervical osteomyelitis after upper gastrointestinal endoscopy: a rare consequence of a routine procedure
}

\author{
Kishan Rajdev 조 , Shayan Shahidi, Samantha Goh, Leonard Liew
}

Otolaryngology, Royal Wolverhampton Hospitals NHS Trust, Wolverhampton, UK

Correspondence to Kishan Rajdev;

krajdev@doctors.org.uk

Accepted 7 February 2022
Check for updates

(C) BMJ Publishing Group Limited 2022. No commercial re-use. See rights and permissions. Published by BMJ.

To cite: Rajdev K, Shahidi S,
Goh S, et al. BMJ Case
Rep 2022;15:e247977.
doi:10.1136/bcr-2021-
247977

\section{DESCRIPTION}

A 72-year-old man presented following an unremarkable oesophago-gastro-duodenoscopy for dysphagia and weight loss. Hours after, he developed a sore throat and restricted neck movements. $\mathrm{He}$ presented 4 days later, lethargic and febrile with worsening dysphagia to solids. Flexible nasendoscopy exhibited fullness of the posterior nasopharynx and pooling of saliva around the right supraglottis, and so a contrast-enhanced CT scan of the neck and thorax was performed (figure 1). This demonstrated fatty stranding around the longus colli muscle fibres suggesting a diagnosis of retropharyngeal calcific tendinitis. While no definite calcifications were visualised, it was thought to be too early in the disease process for these to manifest. A shallow retropharyngeal collection from the anterior arch of the atlas to the upper border of C3 vertebra was also identified, with no significant peripheral enhancement nor any mediastinal extension.

However, clinical assessment and multidisciplinary discussion favoured an infective cause, precipitated by iatrogenic trauma following upper gastrointestinal endoscopy. The patient was commenced on broad-spectrum antibiotics and blood cultures soon yielded Staphylococcus aureus.

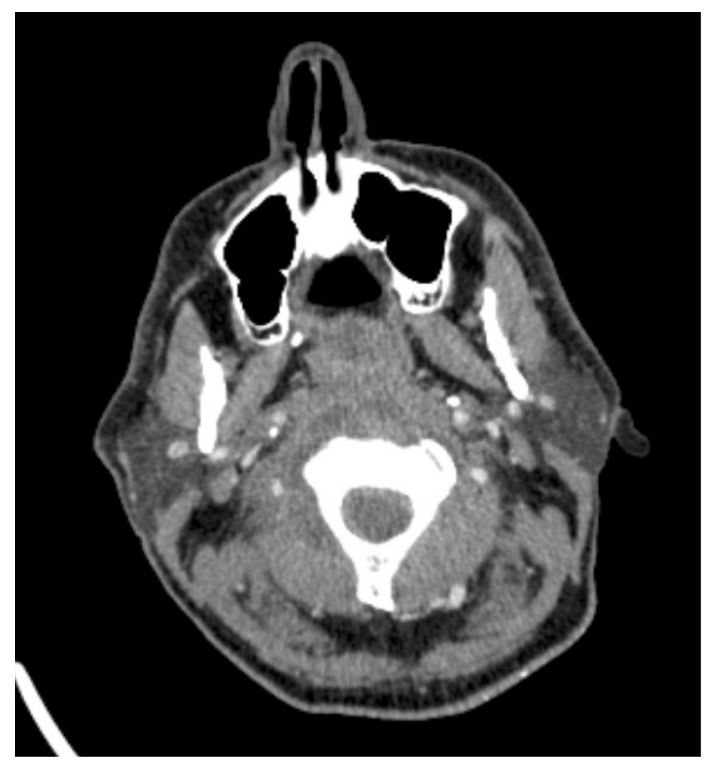

Figure 1 Contrast-enhanced CT neck at index admission. Axial view; prevertebral, retropharyngeal fluid collection without peripheral enhancement around the upper border of C3 vertebra.

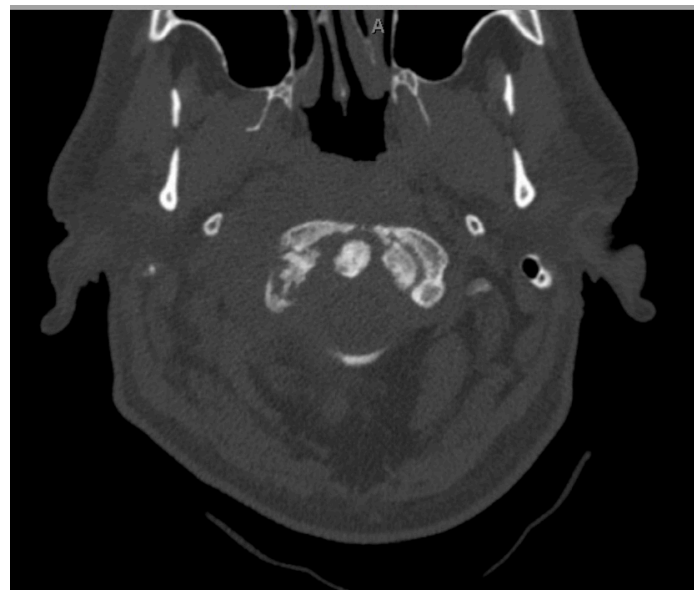

Figure 2 Contrast-enhanced CT neck, interval of 5 months. Axial view; erosion of right atlanto-occipital joint.

His symptoms improved significantly with 3 days of intravenous dexamethasone and over 2 weeks of intravenous antibiotics (flucloxacillin for 5 days then teicoplanin on an outpatient parenteral antibiotic therapy (OPAT) basis for 12 days). Unfortunately, he subsequently experienced progressive neck pain and was re-admitted 4 months after cessation of this course of antibiotics. An interval CT scan and MRI identified upper cervical and skull base osteomyelitis, with bony erosion most prominent at C1, C2 and the right sided atlanto-occipital joint (figure 2). A retropharyngeal phlegmon was again present,

\section{Patient's perspective}

The aftermath has taken up the better part of my life this year. My situation has impacted upon me in a number of ways, all in equal measure.

Stress and worry have been in the background throughout, as I was concerned that the outcome looked bleak.

The not knowing if the infection (Staphylococcus aureus), could be eradicated, and how much damage would I be left with, and what quality of life I could expect afterwards, due to pain and restricted movement. Not knowing if my condition, regarding bone erosion, would get worse and at what speed, is always on my mind.

I feel that my recovery has been slow, and was informed that only time will tell whether I will totally recover from my experience! 


\section{Learning points}

- While rare, trauma to the pharyngeal mucosa at the time of invasive procedures such as upper gastrointestinal endoscopy can result in significant consequences such as deep neck space infection.

- Care must be taken during the consent process to explain all material risks to which a patient may attach significance, as per Montgomery legislation (2015).

- In cases with deep neck space infection, it is crucial to identify and initiate management promptly given the proximity to the airway, prevertebral and mediastinal compartments.

in the absence of any discrete collection amenable to drainage. A contrast swallow showed no evidence of perforation. The patient completed a 3 month course of intravenous antibiotic therapy (flucloxacillin with rifampicin for 6 weeks then intravenous teicoplanin on an OPAT basis for 8 weeks). His cervical spine was concurrently immobilised for 10 weeks in a collar, with no subsequent instability seen on flexion-extension radiographs. Neurosurgical review at 1 month following cessation of antibiotics exhibited no evidence of neurological compromise and inflammatory markers had resolved to within normal limits, at which point the patient was discharged from follow-up.

Only a handful of similar cases are described in the literature in this context. ${ }^{12}$ Deep neck space infection carries great morbidity and mortality ${ }^{3}$ - prevertebral compartment involvement here resulted in subsequent skull base and upper cervical osteomyelitis, and this previously active 72-year-old patient faced a prolonged recovery period to be able to resume his prior daily activities.

One can reflect on the Montgomery legislation (2015) for consent in the United Kingdom, which established a duty of care to warn of material risks ${ }^{4}$ to which 'a reasonable person in the patient's position would be likely to attach significance'. Complications such as in this case are rare but indeed significant-and so we invite endoscopic practitioners performing these frequent and usually uneventful procedures to consider incorporating them into their process in obtaining informed consent.

Acknowledgements We thank Dr Sanjay Vydianath, Consultant Head and Neck Radiologist, for his input during the course of this patient's management.

Contributors KR, SS planned and outlined the case report. KR, SS, SG, LL contributed to the article content and revisions leading to final submission. KR takes responsibility as guarantor for the work

Funding The authors have not declared a specific grant for this research from any funding agency in the public, commercial or not-for-profit sectors.

Competing interests None declared.

Patient consent for publication Consent obtained directly from patient(s).

Provenance and peer review Not commissioned; externally peer reviewed.

Case reports provide a valuable learning resource for the scientific community and can indicate areas of interest for future research. They should not be used in isolation to guide treatment choices or public health policy.

\section{ORCID iD}

Kishan Rajdev http://orcid.org/0000-0003-3431-1221

\section{REFERENCES}

1 Bonaddio V, Herman Z, Armstrong J, et al. Vague neck pain following a gastrointestinal procedure: a rare case presentation of vertebral osteomyelitis and cervical epidural abscess. Spinal Cord Ser Cases 2020;6:40.

2 Chen Y, Kim B-J, Lee S-H, et al. High thoracic spinal infection following upper gastrointestinal work-up. J Clin Neurosci 2007;14:1132-5.

3 Almuqamam M, Gonzalez FJ, Kondamudi NP. Deep neck infections. In: StatPearls. Treasure island (FL): StatPearls Publishing, 2021.

4 Chan SW, Tulloch E, Cooper ES, et al. Montgomery and informed consent: where are we now? BMJ 2017;357:j2224.

Copyright 2022 BMJ Publishing Group. All rights reserved. For permission to reuse any of this content visit

https://www.bmj.com/company/products-services/rights-and-licensing/permissions/

BMJ Case Report Fellows may re-use this article for personal use and teaching without any further permission.

Become a Fellow of BMJ Case Reports today and you can:

- Submit as many cases as you like

- Enjoy fast sympathetic peer review and rapid publication of accepted articles

- Access all the published articles

Re-use any of the published material for personal use and teaching without further permission

Customer Service

If you have any further queries about your subscription, please contact our customer services team on +44 (0) 2071111105 or via email at support@bmj.com.

Visit casereports.bmj.com for more articles like this and to become a Fellow 